\title{
Preventive Effects of Whey Mineral Concentrate on the Development of Hypertension in SHR
}

\author{
Tomohiro Mitsubori, Takako TomitA, ${ }^{*}$ Masahiko IkedA, \\ Takeshi ONDA, and Isao TOMITA \\ School of Pharmaceutical Sciences, University of Shizuoka, \\ Shizuoka 422, Japan
}

(Received June 4, 1990)

\begin{abstract}
Summary Preventive effects of whey mineral concentrate which contained most of the milk minerals and low molecular weight whey protein on the development of hypertension in spontaneously hypertensive rats (SHR) were investigated. SHR after weaning were fed the experimental regimen (whey mineral diet or control diet) and maintained on these diets for approx. 10 weeks. A significant inhibition of development of hypertension was observed in the 4th week with male SHR fed the whey mineral diet compared with sex-matched SHR fed the control diet supplemented with a $\mathrm{NaCl}$ equivalent. The decrease in blood pressure became more pronounced as the period proceeded. The average blood pressure in male SHR at the end of the experiment was $213 \mathrm{mmHg}$ (whey mineral group) and $236 \mathrm{mmHg}$ in the control group. A similar result was obtained with female SHR. Accompanying attenuation of blood pressure, urinary excretion of $\mathrm{Na}$ and retention of $\mathrm{Ca}$ were enhanced by ingestion of the whey mineral concentrate. Blood pressure correlated inversely with urinary $\mathrm{Na}$ excretion $(r=-0.62)$, and positively with urinary $\mathrm{Ca}$ excretion $(r=0.78)$. Which factor in whey mineral concentrate mainly contributes to these effects, remains unclarified.
\end{abstract}

Key Words: SHR, blood pressure, $\mathrm{Na}$ and $\mathrm{Ca}$ excretion, whey mineral concentrate, hypotensive effects

Essential hypertension is a prevalent public health problem throughout the world. As Dahl proposed in 1954 [1], hypertension develops through the interplay of genetic factors and environmental factors such as salt ingestion. The connection between dietary salt intake and hypertension has been revealed by epidemiological

\footnotetext{
*To whom correspondence should be addressed.
} 
observations [1,2] and by experimental studies [3]. There is a positive correlation between the prevalence of hypertension and sodium intake among separate populations. The highest level of sodium intake and the greatest prevalence of hypertension are found among the Japanese, especially those residing in northern Japan. Thus, the curtailing of dietary salt intake has been one of the social goals in Japanese public health. In a population with high sodium intake, a modest change in sodium intake may result in a great change in blood pressure, as suggested by Laragh and Pecker [4].

In contrast to salt intake, an increase in some dietary electrolytes such as $\mathrm{K}$, $\mathrm{Ca}$, and $\mathrm{Mg}$ seems to facilitate a decrease in blood pressure. Numerous investigations have indicated that dietary potassium intake tends to be inversely related to blood pressure in men [5] and experimental animals [6]. The ratio of sodium to potassium intake is associated more closely with blood pressure than is sodium intake, as stated by Langford and Watson [7], Page et al. [8], and Paveh [5]. Furthermore, there is an inverse relationship between dietary $\mathrm{Ca}$ intake and blood pressure $[9,10]$. Magnesium deficiency has also been revealed as an important dietary factor in cardiovascular disease in some epidemiological studies [11-13]. Despite various epidemiological reports on beneficial effects of $\mathrm{K}, \mathrm{Ca}$, and $\mathrm{Mg}$, a higher intake of these electrolytes is always associated with a higher intake of milk so that it is not statistically possible to dissociate the effects of these electrolytes in milk from the antihypertensive effects of milk itself. In addition, hypotensive effects of milk protein were reported by Ikeda et al. [14].

Whey mineral concentrate contains high concentrations of beneficial electrolytes in natural balance along with low molecular weight milk protein; especially, milk has a $\mathrm{K} / \mathrm{Na}$ ratio of approx. 3 and an abundance of $\mathrm{Ca}$. Therefore, we undertook this study to evaluate the potential contribution of whey mineral concentrate to the regulation of blood pressure in spontaneously hypertensive rats(SHR), which are the closest model of human essential hypertension. Evidence presented here indicates that whey mineral concentrate acts as a moderate depressant in SHR.

\section{MATERIALS AND METHODS}

Experimental diets. Whey mineral concentrate was prepared by removal of whey protein (MW >50,000) through ultrafiltration, crystallizing out of the lactose in the filtrate, and spray-drying of the resulting supernatant. The composition of the whey mineral concentrate used in this experiment was as follows: water, $6.0 \%$; ash, 18.0\%; total nitrogen, 1.0\%; sodium, 1.26\%; potassium, 5.4\%; calcium, $0.27 \%$; magnesium, 0.18\%; phosphorus, 0.72\%; iron, $36.6 \mathrm{mg} \%$; vitamin $\mathrm{B}_{1}, 0.6 \mathrm{mg} \%$; vitamin $\mathrm{B}_{2}, 2.5 \mathrm{mg} \%$; vitamin $\mathrm{B}_{6}, 0.25 \mathrm{mg} \%$; vitamin $\mathrm{B}_{12}, 0.28 \mu \mathrm{g} \%$; niacin, $2.0 \mathrm{mg} \%$; and pantothenic acid, $5.7 \mathrm{mg} \%$.

The whey mineral diet (WM diet) contained whey mineral concentrate (33\%, $\mathrm{w} / \mathrm{w}$ ) in CA-1 (Clea, Tokyo). In the control diet, the concentrate was replaced by 
an equivalent amount of $\mathrm{NaCl}$ and lactose.

Animal treatment. SHR, originally provided by Professor K. Okamoto of Kinki University Medical School, and maintained by brother-sister breeding in our laboratory, were used. Fourteen male SHR and 8 female SHR at weaning were divided into two groups; one group received the whey mineral diet while the other group received the control diet during the experimental period of 11 weeks $\left(\sigma^{7}\right)$ or 9 weeks (우). They were given free access to food and water.

During the last week, they were housed individually in metabolic cages so that urinary samples could be collected, and the consumption of food and water were also measured. Blood was withdrawn from the abdominal aorta under light anaesthesia.

Blood pressure measurement. Blood pressure was measured by the tail cuff method once a week in unanesthetized rats by means of a photoelectric detector (Ueda UR-1000, Tokyo).

Analysis of samples. Serum and urinary $\mathrm{Na}, \mathrm{K}$, and $\mathrm{Ca}$ were analyzed by atomic absorption spectrophotometry (Nippon Jarrel-Ash AA880, Kyoto).

\section{RESULTS}

\section{Composition of whey mineral diet}

The composition of the WM diet, which contained 33\% whey mineral concentrate, is shown in Table 1. Although the control diet was supplemented with the theoretically equivalent amount of $\mathrm{NaCl}$, analysis showed the $\mathrm{WM}$ diet to contain a slightly higher $(0.18 \%)$ amount of $\mathrm{Na}$. The contents of $\mathrm{K}$ and $\mathrm{Ca}$ in the $\mathrm{WM}$ diet were approx. 5 and 2 fold, respectively, higher compared with those of the control diet due to their high concentration in the WM concentrate (Table 1).

\section{Changes in body weight and blood pressure}

The growth rates of male and female SHR fed the WM diet were similar to those of the control group throughout the experimental period. Both groups ingested similar amounts of food daily (see the legend to Table 3). The blood pressure of male SHR at weaning was $123 \mathrm{mmHg}$. In the control group it elevated to $186 \mathrm{mmHg}$ at the 4 th week, $217 \mathrm{mmHg}$ at the 8th week, and $236 \mathrm{mmHg}$ at the end of the experimental period. In the WM group, however, a significant inhibition of development of hypertension began to be observed at the 4th week: the

Table 1. Mineral contents (\%) in the experimental and control diets.

\begin{tabular}{lcccc}
\hline Diets & $\mathrm{Na}$ & $\mathrm{K}$ & $\mathrm{Ca}$ & Water \\
\hline Control & 1.25 & 0.559 & 1.22 & 8.5 \\
Whey mineral diet & 1.43 & 2.55 & 2.40 & 11.3 \\
\hline
\end{tabular}

The whey mineral diet contains whey mineral concentrate (33\%) in CA-1 (Clea, Tokyo), while in the control diet the whey mineral concentrate was replaced by an equivalent amount of $\mathrm{NaCl}$ and lactose.

Vol. 9, No. 2, 1990 
blood pressure was $7 \%$ lower at the 4 th week, $9 \%$ lower at the 8 th week, and $10 \%$ lower at the 11th week than the corresponding control group values. The inhibition by the WM diet was highly significant by ANOVA analysis (Fig. 1a). A

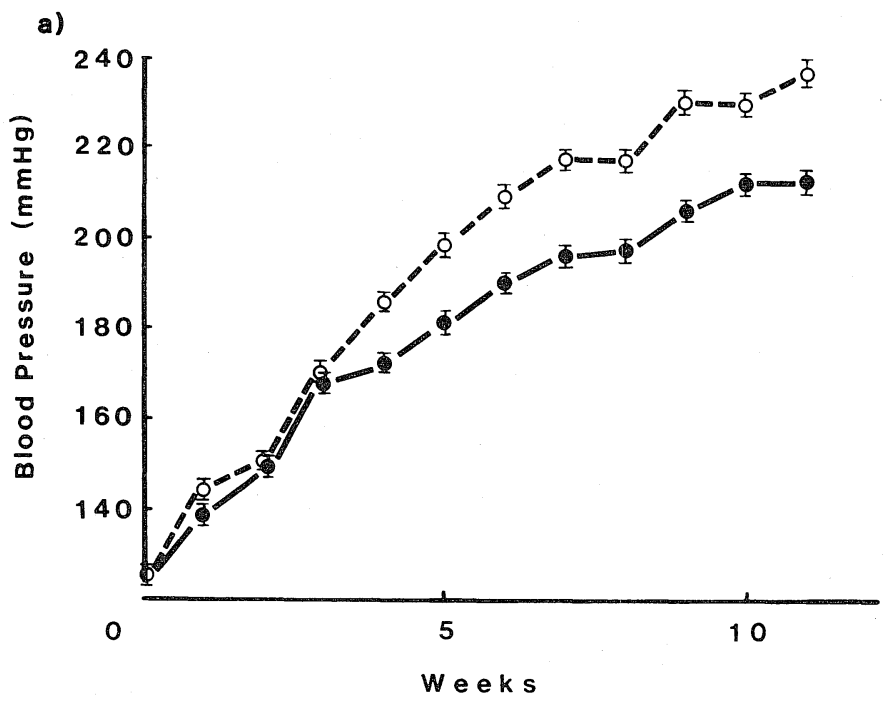

b)

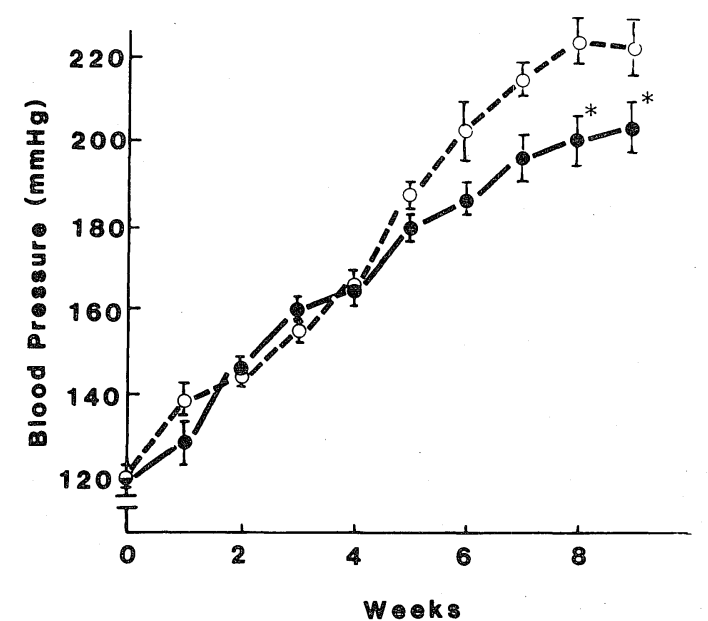

Fig. 1. Inhibition of development of hypertension in SHR by ingestion of whey mineral concentrate. Male (a) and female (b) SHR were divided into two groups each with 7 rats $\left(\sigma^{7}\right)$ and 4 rats (우) at weaning. One group (- - ) was maintained during the experimental period on the whey mineral diet, while the other (-- --$)$ received the control diet. Blood pressure was measured by tail-cuff plethysmography. Each point and vertical bar indicate mean $\pm \mathrm{SE}$ for the number of rats used. a) Significance: $p<0.01$ by ANOVA analysis. b) *Significance: $p<0.05$ by Student's $t$-test.

J. Clin. Biochem. Nutr. 
similar result was obtained with female SHR (Fig. 1b).

\section{Serum electrolyte concentration}

Table 2 shows the concentration of serum electrolytes. In both sexes, the $\mathrm{Na}$ level remained unaltered by the dietary regimen, but the potassium levels was approx. 14-15\% higher in the WM group than that of the control, reflecting the higher potassium ingestion in the WM diet. In fact, the WM group ingested 4 times more potassium daily than the control (See below). Despite a twofold greater content and intake of $\mathrm{Ca}$ in the WM diet, the serum $\mathrm{Ca}$ level of both male and female WM groups was significantly lower in the control group.

Table 2. Changes in serum electrolytes in SHR fed the WM diet.

\begin{tabular}{|c|c|c|c|c|}
\hline Group & $(n)$ & $\begin{array}{l}\text { Serum } \mathrm{Na} \\
\text { (mEq/liter) }\end{array}$ & $\begin{array}{c}\text { Serum K } \\
\text { (mEq/liter) }\end{array}$ & $\begin{array}{l}\text { Serum Ca } \\
(\mathrm{mEq} / \text { liter })\end{array}$ \\
\hline Male & & mean \pm & & \\
\hline Control & (7) & $141 \pm 0.98$ & $6.6 \pm 0.18$ & $5.4 \pm 0.022$ \\
\hline Whey mineral & (7) & $143 \pm 1.8$ & $7.7 \pm 0.25^{* *}$ & $4.8 \pm 0.079 *$ \\
\hline \multicolumn{5}{|l|}{ Female } \\
\hline Control & (4) & $143 \pm 0.48$ & $4.2 \pm 0.075$ & $5.3 \pm 0.14$ \\
\hline Whey mineral & (4) & $140 \pm 1.5$ & $5.3 \pm 0.23^{*}$ & $4.9 \pm 0.075^{*}$ \\
\hline
\end{tabular}

Two groups each of male and female SHR at weaning were fed the whey mineral or control diet for 11 weeks $\left(\sigma^{1}\right)$ or 9 weeks $($ 우). Serum $\mathrm{Na}, \mathrm{K}$, and $\mathrm{Ca}$ were measured by atomic absorption spectrophotometry. ${ }^{*}$ Significance: $p<0.05$ by Student's $t$-test; ${ }^{* *}$ Significance: $p<0.01$ by Student's $t$-test.
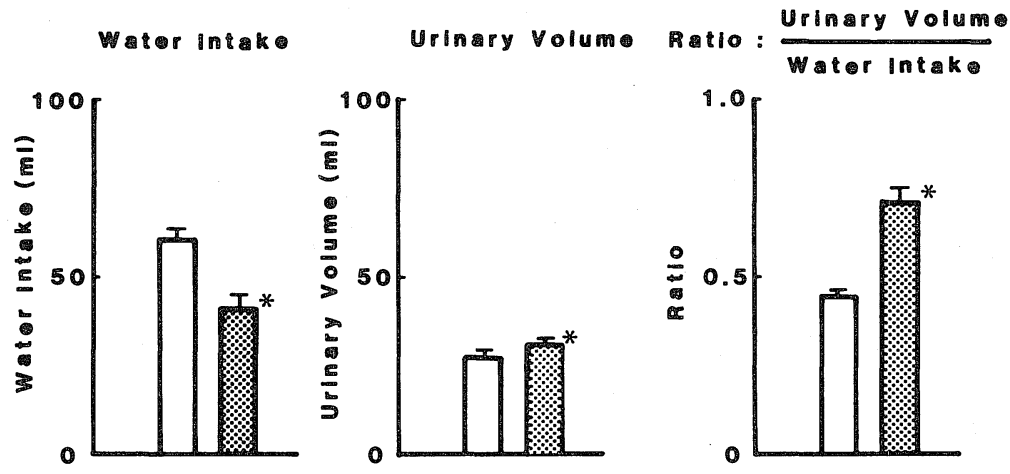

Fig. 2. Effects of whey mineral ingestion on water balance in SHR. Two groups of male SHR at weaning were fed either whey mineral (厤) or control ( $\square$ ) diet. They were housed individually in metabolic cages during the last week of the experimental period. Each column and vertical bar indicate mean \pm SE for the number of rats used (7). *Significance: $p<0.01$ by Student's $t$-test.

Vol. 9, No. 2, 1990 


\section{Water and electrolyte balance}

Figure 2 shows the water balance in experimental and control male SHR. Although the difference in the urinary volume between the two groups was small, the water balance (ratio of urinary volume to water intake) was higher in the WM group than in the control group, due to less water intake by the former.

Figure 3 shows the urinary excretion of electrolytes in male and female SHR. For males, sodium excretion was increased by $37 \%$ and potassium excretion was 6.3-fold greater in the WM group than in the control. The greater excretion of potassium in the WM group definitely results from the greater ingestion of

a)
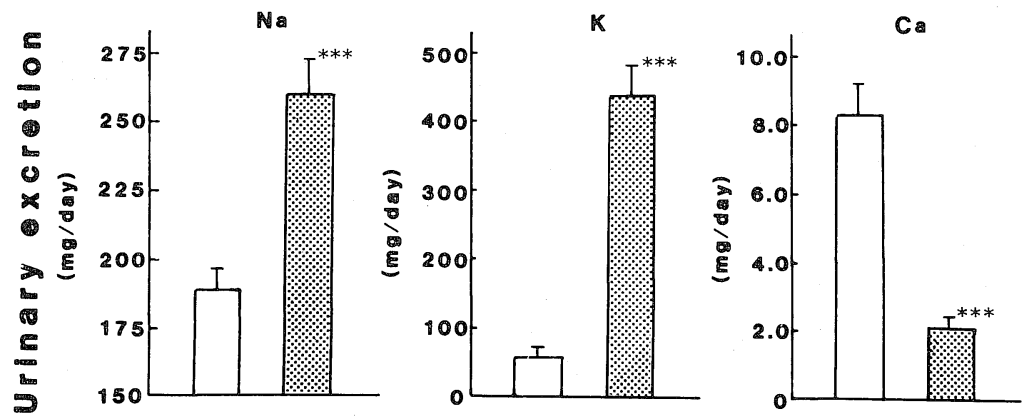

b)

Na

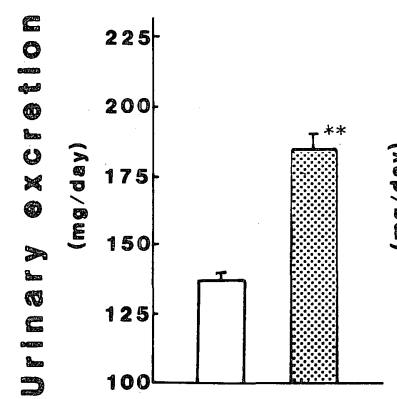

K

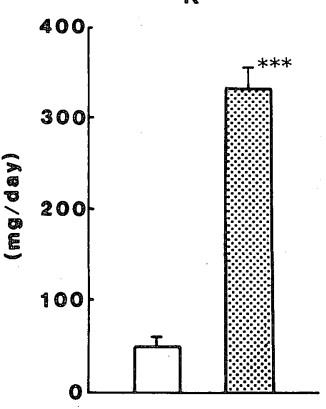

Cะ

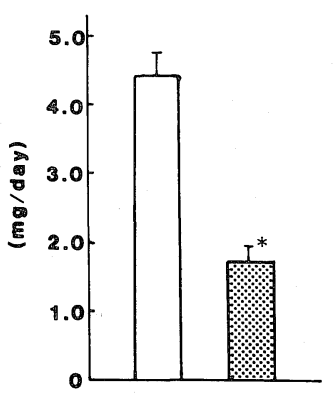

Fig. 3. Effects of whey mineral ingestion on urinary electrolyte excretion in SHR. Experimental details are described in the legend to Fig. 2. Each column and vertical bar indicate mean $\pm \mathrm{SE}$ for the number of rats used $\left(\sigma^{7}, 7\right.$; 우, 4). a) Male SHR, b) Female SHR. Whey mineral diet (咯), Control diet ( $\square$ ). *Significance: $p<0.05$ by Student's $t$-test; ${ }^{* *}$ significance: $p<0.01$ by Student's $t$-test; ${ }^{* * *}$ significance: $p<0.001$ by Student's $t$-test. 
Table 3. Changes in Na balance in SHR due to whey mineral ingestion.

\begin{tabular}{|c|c|c|c|c|}
\hline Group & $(n)$ & $\begin{array}{c}\mathrm{Na} \\
\text { intake } \\
(\mathrm{mg} / \mathrm{day})\end{array}$ & $\begin{array}{l}\text { Urinary } \\
\text { excretion } \\
\text { (mg/day) }\end{array}$ & $\begin{array}{c}\text { Urinary } \\
\text { excretion/Intake }\end{array}$ \\
\hline Male & & \multicolumn{2}{|c|}{ mean $\pm \mathrm{SE}$} & \\
\hline Control & (7) & $244 \pm 7.2$ & $189 \pm 7.2$ & $0.774 \pm 0.023$ \\
\hline Whey mineral & (7) & $241 \pm 19$ & $259 \pm 14^{* * *}$ & $1.09 \pm 0.060^{* * *}$ \\
\hline \multicolumn{5}{|l|}{ Female } \\
\hline Control & (4) & $180 \pm 3.7$ & $142 \pm 4.7$ & $0.785 \pm 0.026$ \\
\hline Whey mineral & (4) & $188 \pm 8.2$ & $185 \pm 10^{* *}$ & $1.01 \pm 0.095$ \\
\hline
\end{tabular}

Table 4. Changes in $\mathrm{Ca}$ balance in SHR due to whey mineral ingestion.

\begin{tabular}{lcccc}
\hline Group & $(n)$ & $\begin{array}{c}\text { Ca } \\
\text { intake } \\
(\mathrm{mg} / \text { day })\end{array}$ & $\begin{array}{c}\text { Urinary } \\
\text { excretion } \\
(\mathrm{mg} / \text { day })\end{array}$ & $\begin{array}{c}\text { Urinary } \\
\text { excretion/Intake } \\
\left(\times 10^{2}\right)\end{array}$ \\
\hline Male & \multicolumn{2}{c}{ mean $\pm \mathrm{SE}$} \\
$\quad$ Control & $(7)$ & $238 \pm 7.2$ & $8.26 \pm 1.0$ & $3.47 \pm 0.42$ \\
Whey mineral & $(7)$ & $405 \pm 33^{* * *}$ & $2.02 \pm 0.22^{* * *}$ & $0.507 \pm 0.057^{* * *}$ \\
\hline Female & & & & \\
Control & $(4)$ & $176 \pm 3.6$ & $4.55 \pm 0.80$ & $2.58 \pm 0.44$ \\
Whey mineral & $(4)$ & $316 \pm 14$ & $1.60 \pm 0.41^{*}$ & $0.452 \pm 0.17^{* *}$ \\
\hline
\end{tabular}

SHR are treated as described in the legend to Fig. 1. *Significance: $p<0.05$ by Student's $t$-test; ${ }^{* *}$ significance: $p<0.01$ by Student's $t$-test; ${ }^{* * *}$ significance: $p<0.001$ by Student's $t$-test.

potassium [ $\mathrm{K}$ intake (mg/day): $431 \pm 35(7)$ in WM group vs. $109 \pm 8.6(7)$ in control group]. However, $75 \%$ less Ca was excreted in the WM group, which ingested more $\mathrm{Ca}$ than the control group. Similar results were obtained for female SHR.

Tables 3 and 4 show $\mathrm{Na}$ and $\mathrm{Ca}$ balances during the last week. Although the $\mathrm{Na}$ intake and urinary volume were similar in the WM and control groups, more sodium was excreted in the WM group so that the $\mathrm{Na}$ balance became significantly higher in male SHR fed the WM diet. In contrast to $\mathrm{Na}, \mathrm{Ca}$ was ingested more in the WM group whereas it was excreted less into the urine. Thus, the Ca balance became less in the WM group.

As shown in Fig. 4, there were significant correlations between blood pressure and $\mathrm{Na}$ or $\mathrm{Ca}$ excretion.

\section{DISCUSSION}

Fujita and Sato [15] demonstrated that supplementation with $0.2 \% \mathrm{KCl}$ to drinking water containing $1 \% \mathrm{NaCl}$ significantly moderated the development of

Vol. 9, No. 2, 1990 
a)

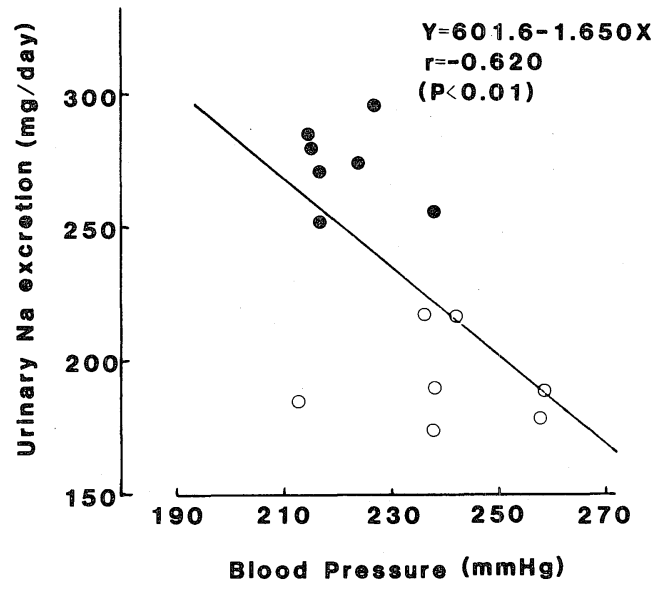

b)

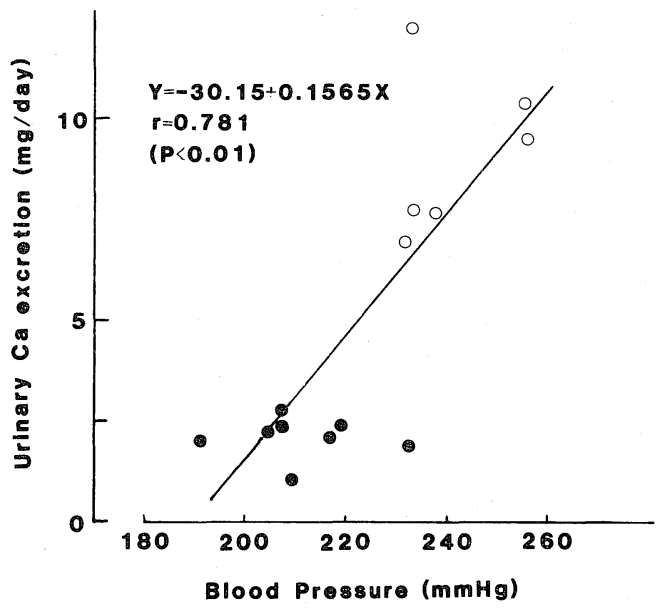

Fig. 4. Correlation between blood pressure and urinary $\mathrm{Na}$ and $\mathrm{Ca}$ excretion in male SHR maintained on the experimental diet. SHR were treated as described in the legend to Fig. 1. a) $\mathrm{Na}$ excretion, b) $\mathrm{Ca}$ excretion: whey mineral group; $\mathrm{O}$, control group.

deoxycorticosterone acetate (DOCA)-salt hypertension. In our preliminary experiment (unpublished), DOCA-salt hypertensive rats were given whey mineral concentrate containing an equivalent amount of $\mathrm{K}$ as in the above experiment through their drinking water. We found that the whey mineral concentrate was more potent in attenuation of development of hypertension than $\mathrm{K}$ itself. There was, however, 
some difficulty in feeding the concentrate (10\%) in drinking water. Sugden et al. [16] maintained 7-week-old female SHR on a dietary regimen supplemented with $2 \% \mathrm{~K}$, and found that $\mathrm{K}$ had a moderate hypotensive effect. In our experiment we used weanling male and female SHR, which were fed a WM (33\%) diet for approx. 10 weeks. These SHR ingested slightly more K compared with SHR in the experiment done by Sugden et al. [16]. Our WM diet significantly reduced the development of hypertension beginning at the 4th to 5th week both in male and female SHR. Accompanying the prevention of hypertension, there was an increase in water balance and urinary Na-excretion.

Various investigators have suggested that $\mathrm{Ca}$ handling is altered in SHR compared with that in WKY. Walczyk and McCarron [17] observed that in SHR there was an increase in urinary $\mathrm{Ca}$ excretion with a decrease in ionized serum $\mathrm{Ca}$ and that the blood pressure was reduced following the supplementation of $\mathrm{Ca}$ in the diet. Despite there being two times more $\mathrm{Ca}$ in the WM diet, the urinary $\mathrm{Ca}$ excretion was significantly reduced by the ingestion of the WM concentrate. Since it is well known that the absorption of milk $\mathrm{Ca}$ is better than that of the element in other foods, the low urinary $\mathrm{Ca}$ excretion can not be ascribed to a reduction in intestinal $\mathrm{Ca}$ absorbance in the WM group. Therefore, the consequent increase in Ca-retention might be partly involved in the hypotensive effect of the WM concentrate. A high $\mathrm{K}$ or $\mathrm{Ca}$ content and the low ratio of $\mathrm{Na} / \mathrm{K}$ in the $\mathrm{WM}$ diet seem to be related to the hypotensive effect of the WM concentrate. However, our preliminary data in SHR [18] suggests that WM exerts a more potent antihypertensive effect than an equivalent K-supplementation. Besides its effect on blood pressure, the WM concentrate significantly suppresses the plasma lipid peroxide level estimated as thiobarbituric acid-reactive substances (TBARS) and platelet aggregation [19]. It is reported that several proteins such as those of fish [20], soy bean [21], and milk [15] have a hypotensive effect, possibly due to the high content of sulfur-containing amino acids and taurine in them. Interestingly, such sulfur-containing amino acids were claimed to have an antioxidative property [22].

What factors in the WM concentrate contribute to the beneficial effects on blood pressure control, Ca retention, plasma TBARS, and platelet aggregation needs to be investigated.

\section{REFERENCES}

1. Dahl, L.K., and Love, R.A. (1954): Evidence for relationship between sodium (chloride) intake and human essential hypertension. Arch. Intern. Med., 94, 523-531.

2. Gleiberman, L. (1973): Blood pressure and dietary salt in human populations. Ecol. Food Nutr., 2,143-156.

3. Meneely, G.R., and Dahl, L.K. (1961): Electrolytes in hypertension: The effects of sodium chloride. The evidence from animal and human studies. Med. Clin. North Am., 45, 271-283.

4. Laragh, J.H., and Pecker, M.S. (1983): Dietary sodium and essential hypertension: Some myths, hopes and truths. Ann. Intern. Med., 98 (part 2), 735-743.

Vol. 9, No. 2, 1990 
5. Paveh, K. (1984): Potassium supplements and hypertension. Lancet, I, 1189-1190.

6. Skrabal, F., Aubock, J., and Hortnagel, H. (1981): Low sodium/high potassium diet for prevention of hypertension: Probable mechanism of action. Lancet, II, 895-900.

7. Langford, H.G., and Watson, R.L. (1973): Electrolytes, environment and blood pressure. Clin. Sci. Mol. Med., 45, 111-113.

8. Page, L.B., Vandevert, D.E., and Nader, K. (1981): Blood pressure of Qash'qai pastoral nomads in Iran in relation to culture, diet, and body form. Am. J. Clin. Nutr., 52, 146-151.

9. McCarron, D.A., Morris, C.D., Henry, H.J., and Stanton, J.L. (1984): Blood pressure and nutrient intake in the United States. Science, 224, 1392-1398.

10. Resnick, L.M. (1985): Calcium and hypertension: The emerging connection. Ann. Intern. Med., 103, 944-946.

11. Petersen, B., Schroll, M., and Christiansen, C. (1977): Serum and erythrocyte magnesium in normal elderly Danish people. Acta Med. Scand., 201, 31-34.

12. Schroeder, H.A. (1960): Relation between normality from cardiovascular disease and treated water supplies. Variation in states and 163 largest municipalities of the United States. JAMA, 172, 1902-1908.

13. Kesteloot, H. (1984): Urinary cations and blood pressure population studies. Ann. Clin. Res., 16, Suppl. 43, 72-80.

14. Ikeda, K., Motizuki, S., Nara, Y., Horie, R., and Yamori, Y. (1987): Effects of milk protein and fat intake on blood pressure and the incidence of cardiovascular diseases in strokeprone spontaneously hypertensive rats (SHRSP). J. Nutr. Sci. Vitaminol., 33, 31-36.

15. Fujita, T., and Sato, Y. (1984): Changes in renal and central noradrenergic activity with potassium in DOCA-salt rats. Am. J. Physiol., 246, F670-F675.

16. Sugden, A.L., Bean, B.L., and Straw, J.A. (1987): $\mathrm{Na}^{+}, \mathrm{K}^{+}$and water balance in young spontaneously hypertensive rats: Relationship to blood pressure after high $\mathrm{K}^{+}$treatment. Clin. Sci., 72, 321-327.

17. Walczyk, M.H., and McCarron, D.A. (1987): Calcium and hypertension. Compr. Ther., 13 (11), 10-16.

18. Mitsubori, T., Tomita, T., Ikeda, M., Sano, M., and Tomita, I. (1989): Inhibitory effects of milk minerals on salt-induced high blood pressure and lipid peroxide levels in SHR. Jpn. Heart J., 30, 567.

19. Mitsubori, T., Tomita, T., Ikeda, M., Sano, M., and Tomita, I.(1988): Effects of milk minerals on blood pressure and plasma lipid peroxide levels in SHR. Jpn. Heart J., 29, 582.

20. Yamori, Y., Horie, R., Nara, Y., Kihara, M., Fujiwara, K., Nabika, T., Mano, M., and Ikeda, I. (1979): Nutritional causation and prevention of cardiovascular diseases-experimental evidence in animal models and man, in Nutritional Prevention of Cardiovascular Disease, ed. by Lovenberg, W. and Yamori, Y., Academic Press, Orlando, pp. 37-51.

21. Yamori, Y., Horie, R., Ikeda, K., Nara, Y., and Lovenberg, W. (1979): Prophylactic effects of dietary protein on stroke and its mechanism, in Prophylactic Approach to Hypertensive Diseases, ed. by Yamori, Y., Lovenberg, W. and Freis, E.D., Raven Press, New York, pp. 497-504.

22. Murakami, T., Tsuji, A., and Iizuka, Y. (1988): Effect of nutritional improvement and antihypertensive treatment on blood pressure, cerebral stroke lesions and life-span in SHRSP. Jpn. Heart J., 29, 585. 